\title{
Stem Cells in the Adult Zebrafish Cerebellum: Initiation and Maintenance of a Novel Stem Cell Niche
}

\author{
Jan Kaslin, Julia Ganz, Michaela Geffarth, Heiner Grandel, Stefan Hans, and Michael Brand \\ Biotechnology Center and Center for Regenerative Therapies Dresden, Dresden University of Technology, 01307 Dresden, Germany
}

In the adult CNS, neurogenesis takes place in special niches. It is not understood how these niches are formed during development and how they are maintained. In contrast to mammals, stem cell niches are abundant in zebrafish and also found in other parts of the brain than telencephalon. To understand common characteristics of neural stem cell niches in vertebrates, we studied the origin and architecture of a previously unknown stem cell niche using transgenic lines, in vivo imaging, and marker analysis. We show that bipotent stem cells are maintained in a distinct niche in the adult zebrafish cerebellum. Remarkably, the stem cells are not typical glia but instead retain neuroepithelial characteristics. The cerebellar stem cell niche is generated by the coordinated displacement of ventricle and rhombic lip progenitors in a two-step process involving morphogenetic movements and tissue growth. Importantly, the niche and its stem cells still remain in ventricular contact through a previously unknown derivative of the ventricle. Factors propagated in the ventricle are thought to be important regulators of stem cell activity. To test the requirements of one family of important factors, Fibroblast growth factors, we used zebrafish with an inducible dominant-negative Fgf receptor. Inhibition of Fgf signaling leads to significant reduction of stem cell activity. In contrast to the predominant view, adult neural stem cells in nonmammalian vertebrates show more neuroepithelial than glial characteristics. Nevertheless, retained epithelial properties such as distinct polarization and ventricular contact are critical common determinants to maintain neural stem cell activity in vertebrates.

\section{Introduction}

Most neurons in the vertebrate CNS are generated during embryonic development. However, limited neurogenesis takes place in special microenvironments, stem cell niches, that are maintained into adulthood (Alvarez-Buylla and Lim, 2004). The niche is a key regulator of stem cells in vivo (Fuchs et al., 2004; Decotto and Spradling, 2005). It is not well understood how neural stem cell niches are formed during development and how they are maintained postembryonically.

In the CNS of adult mammals and birds, neurogenic stem cell niches are restricted to one brain region, the telencephalon. In other vertebrates, such as teleost fish, stem cell niches are more abundant and also found in parts of the brain other than the telencephalon (Kaslin et al., 2008). Zebrafish has a widespread life-long neurogenesis that generates many different subtypes of neurons (Zupanc et al., 2005; Adolf et al., 2006; Grandel et al., 2006). The progenitors form 16 distinct niches that are distributed along the entire rostrocaudal brain axis (Grandel et al., 2006). This makes zebrafish a suitable model to study how stem cell niches from different brain regions are constituted and main-

Received Jan. 6, 2009; revised April 9, 2009; accepted April 13, 2009.

This work was supported by grants from Sigrid Juselius Foundation, Sonderforschungsbereich 655, European Union (EU) ZF-Models, and EU Endotrack. We dedicate this work to Krister Eriksson. We thank Heike Hollak and Anja Machate for excellent technical support. We thank Alexander Picker, Dorian Freudenreich, Minna-Liisa Änkö, and Laurel Rohde for comments on this manuscript. We thank Franseco Argenton and Steve Wilson for sharing reagents.

Correspondence should be addressed to Michael Brand, Biotechnology Center and Center for Regenerative Therapies Dresden, Dresden University of Technology, Tatzberg 47, 01307 Dresden, Germany. E-mail: michael.brand@biotec.tu-dresden.de.

DOI:10.1523/JNEUROSCI.0072-09.2009

Copyright $\odot 2009$ Society for Neuroscience $\quad$ 0270-6474/09/296142-12\$15.00/0 tained. During vertebrate development, neurogenesis in different brain regions follows a strict temporal sequence. In mammals and birds, the generation of cerebellar granule cells is continued postembryonically for several weeks but eventually ceases. Remarkably, in the zebrafish cerebellum abundant life-long neurogenesis takes place. In fact, this brain region shows the most abundant neurogenesis in the adult zebrafish (Grandel et al., 2006). Detailed analysis of an adult brainstem cell niche other than the telencephalon of mammals is missing. To understand common characteristics of neural stem cell niches in vertebrates, we studied the origin and architecture of a novel stem cell niche, the cerebellar stem cell niche, in zebrafish.

We show that neural stem cells are maintained in a highly specialized niche in adult zebrafish. This niche consists of a small pool of distinctly polarized stem cells that are demarcated by apical markers and flanked medially and laterally by two different populations of glia. Stem cells in this niche are bipotent, and express neural stem cell and upper rhombic lip markers. It is thought but has not been shown that radial glia serve as progenitors in the adult CNS of nonmammalian vertebrates. To our surprise, the proliferating stem cells in the cerebellum do not express canonical radial or astroglial markers but retain neuroepithelial characteristics. We show that this distinct stem cell niche is generated in a two step process that initially involves morphogenetic movements and later tissue growth. Because of these processes, upper rhombic lip progenitors and a small portion of the ventricle are displaced deep into the tissue. Importantly, we find that a derivative of the IVth ventricle, the cerebellar recessus, still connects the niche to the ventricular system and that the stem cells remain in direct ventricular contact. Further- 
more, we show that granule neurons and glia are generated in the adult cerebellum. Our results in developing and adult zebrafish show that there is no formation of a prominent external granule layer. Instead, there is a continuous supply of granule precursors from the cerebellar stem cell niche to the granule cell layer. The cells that turn into granule cell precursors molecularly progress and migrate in a similar manner to mammalian granule cells. To test the requirement for Fgf signaling in the adult cerebellar stem cell niche, we used transgenic zebrafish to misexpress a dominant-negative Fgf receptor. We show that inhibition of Fgf signaling significantly reduces stem cell activity in the adult cerebellum.

\section{Materials and Methods}

Zebrafish strains and treatment of fish. Zebrafish were bred and maintained according to standard procedures (Westerfield, 2000). Wild-type experimental fish were from the gol-b1 line in the $\mathrm{AB}$ genetic background. Adult fish were 6-8 months old and had a $24-28 \mathrm{~mm}$ body length. All animal procedures were approved by the Regierungspräsidium Dresden. The $\operatorname{Tg}(g f a p: G F P)$ zebrafish line expresses enhanced green fluorescent protein (EGFP) under the control of the zebrafish $g f a p$ promoter, recapitulating the endogenous GFAP pattern (Bernardos and Raymond, 2006). The $\operatorname{Tg}(E F 1 \alpha: D s R e d 2)$ zebrafish line expresses DsRed2 under the control of the Xenopus Elongation Factor $1 \alpha(E F 1 \alpha)$ promoter (Hans et al., 2009). The EF1 $\alpha$ promoter expresses DsRed2 ubiquitously in the neural tube during early juvenile stages. A single heat shock strongly and uniformly induces $\mathrm{dn}$-fgfr 1 transgene expression for at least $24 \mathrm{~h}$, and daily heat treatments efficiently block Fgf signaling (Lee et al., 2005). The $h s p 70: d n f g f r 1$ construct can interact with all Fgfr subtypes and thereby competitively block signaling downstream of all Fgfr subtypes. $h s p 70: d n-f g f r l$ fish and wild-type siblings were heat induced once and the day $(24 \mathrm{~h})$ after the induction received a $4 \mathrm{~h}$ BrdU pulse before kill. For experiments with the homozygous $h s p 70: d n-f g f r 1$ fish strain, age and size matched control fish were used.

Generation of $\mathrm{Tg}$ (nestin:GFP) transgenic line. Independent BACs containing the genomic nestin locus were obtained from the BACPAC resource center. BAC CH 73-2F9 containing $41 \mathrm{~Kb}$ of the genomic nestin locus was used. The coding sequence of nestin was flanked by $13.5 \mathrm{~Kb}$ upstream and $18.1 \mathrm{~Kb}$ downstream sequence. To make a reporter line, a cassette containing an EGFP-tagged nitroreductase and a polyadenylation signal was recombineered at the starting ATG of exon 1. First, FRTgb-neo-FRT and ntr-EGFP cassettes where amplified by PCR. Then, the cassettes where amplified and merged by Fusion PCR with primers carrying $50 \mathrm{nt}$ of homology of the targeting sequence. Recombineering of the BAC was performed as previously described (Zhang et al., 1998). BAC DNA was purified with an endotoxin-free large construct kit (Nucleobond, Macherey-Nagel) and 25-100 pg of BAC DNA were injected into fertilized eggs at the one cell stage. F0 were raised and incrossed. F1 were identified by visual screening for GFP expression.

Tissue preparation. Exposed brains in skull were fixed at $4^{\circ} \mathrm{C}$ overnight in $2-4 \%$ paraformaldehyde/0.1 M phosphate buffer (PB), $\mathrm{pH}$ 7.5. They were washed twice with $\mathrm{PB}$ and transferred for decalcification and cryoprotection into $20 \%$ sucrose $/ 20 \%$ EDTA in $0.1 \mathrm{M} \mathrm{PB}$, pH7.5. Brains were frozen in $7.5 \%$ gelatin $/ 20 \%$ sucrose and cut at $14 \mu \mathrm{m}$. Sections were stored at $-20^{\circ} \mathrm{C}$.

In vivo imaging and dye injections. Live embryos or zebrafish were anesthetized with $0.1 \%$ tricaine (Sigma), mounted in $1.5 \%$ low-melting point agarose in embryo medium 3 (E3) and imaged with a Leica TCS SP5 confocal microscope. For in vivo imaging of ventricles, dextran rhodamine B $70 \mathrm{kDa}(35 \mathrm{mg} / \mathrm{ml}$, Invitrogen) was slowly injected into the IIIrd or IVth ventricle with a fine glass needle. Skin and bone were carefully removed from the dorsal cranium of juveniles older than $7 \mathrm{dpf}$ and adult fish. Juvenile and adult fish were kept anesthetized in artificial fresh water CSF (McElligott et al., 1998) during imaging.

BrdU labeling. To label cycling cells, zebrafish were immersed in $10 \mathrm{~mm}$ $\mathrm{BrdU}$ (Sigma) solution (Grandel et al., 2006). The BrdU was dissolved in E3 medium and the $\mathrm{pH}$ adjusted to 7.5.

Immunohistochemistry and in situ hybridization. Immunohistochem- istry was performed as previously described (Kaslin et al., 2004; Grandel et al., 2006). Briefly, primary and secondary antibodies were incubated in PBS with $0.3 \%$ TX. Primary antibodies were incubated overnight at $4 \mathrm{C}^{\circ}$ and secondary antibodies for $1 \mathrm{~h}$ at room temperature. The slides were then washed in PBS TX and mounted. Information about the primary antibodies is given in supplemental Table 1, available at www.jneurosci.org as supplemental material. Alexa 488-, 555-, and 633-conjugated secondary antibodies were used for detection (Invitrogen). In situ hybridization and probe generation was performed as previously described (Kaslin et al., 2004). Information about the in situ probes is given in supplemental Table 2, available at www.jneurosci.org as supplemental material. All immunostainings and in situ hybridizations were done on at least three individuals.

Generation of Musashil antibody. The synthetic peptides MESEGSQSNLSSSDS and SMVMRDPVTKRSRGF from the N terminus of zebrafish Musashil were used to generate polyclonal antibodies produced in rabbits according to standard procedures. Specificity of the antibodies was verified by blocking peptide experiments and immunohistochemistry and Western blotting.

Image acquisition and processing. Images were taken with Zeiss-LSMMETA and Leica TCS-SP5 confocal microscopes. To minimize cross talk between the channels in multicolored specimens, sequential image acquisition was performed. Images were processed using ImageJ v.1.32 (http://rsb.info.nih.gov/ij/), Volocity and Adobe Photoshop CS2. Figures were assembled using Adobe Photoshop CS2 and Corel Draw X3.

Cell counting and statistical analysis. We quantified the number of BrdU + cells in every second section $(14 \mu \mathrm{m})$ throughout the whole cerebellar corpus. Statistical significance was tested with a nonpaired Student's $t$ test.

\section{Results \\ Stem cells reside in a distinct location in the adult zebrafish cerebellum}

To separate cells with different proliferative behaviors and to identify cells displaying progenitor potential, we performed a series of BrdU pulse chase experiments in combination with detecting the proliferation markers, proliferating cell nuclear antigen (PCNA) and phospho-histone $\mathrm{H} 3$ (pH3), and histological markers (fluorescent Nissl staining). Two major proliferation zones are present in the cerebellum of adult zebrafish (zone $14 \mathrm{a}$ and b) (Fig. 1; supplemental Fig. S1, available at www.jneurosci.org as supplemental material) (Grandel et al., 2006). The first of these zones is restricted to the dorsal midline of the nonvestibular cerebellar regions, the cerebellar corpus and its anterior extension the valvula cerebelli (Fig. 1; supplemental Fig. S1, available at www.jneurosci.org as supplemental material). The second proliferation zone is found caudolaterally in the caudal lobe of the cerebellum (supplemental Fig. S1, available at www.jneurosci.org as supplemental material). Here, we focus on progenitors in the cerebellar corpus (14a).

Proliferation markers and pulse chase experiments showed that proliferating cells originate from a distinct cap-like structure in the dorsomedial corpus cerebelli and valvula cerebelli (Fig. $1 B, E$; supplemental Fig. S1, available at www.jneurosci.org as supplemental material). This cap-like structure is located in the midline at the interface between the molecular and granular cell layer (Fig. $1 B, E$ ). To identify putative stem cells in the cerebellum, we performed a label retention assay. Cells were designated as label retaining if they retained BrdU over a long time and still displayed a marker of ongoing proliferation (PCNA, pH3). We performed BrdU pulse ( $4 \mathrm{~h}-2 \mathrm{~d}$ ) and long chase experiments (4-6 weeks chase) in combination with a second proliferation marker (PCNA). Long BrdU pulse chase experiments showed that the majority of BrdU-positive cells rapidly migrate out from the cap-like structure (Fig. $1 C-G$ ). Furthermore, BrdU was quickly diluted out in PCNA-positive proliferating cells and 


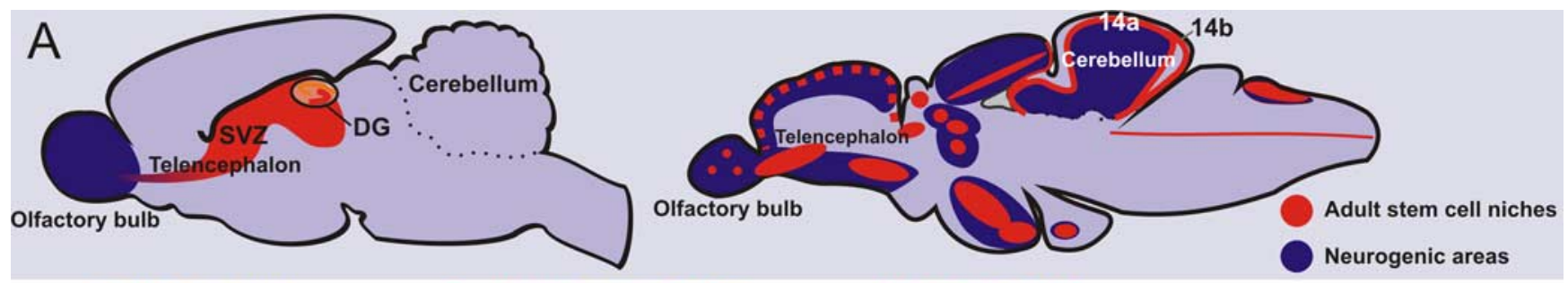

BrdU 2d PCNA

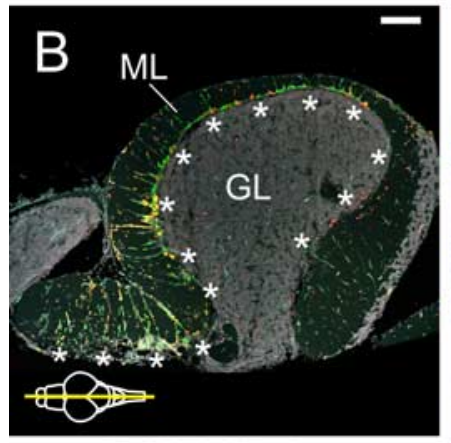

PCNA Nissl

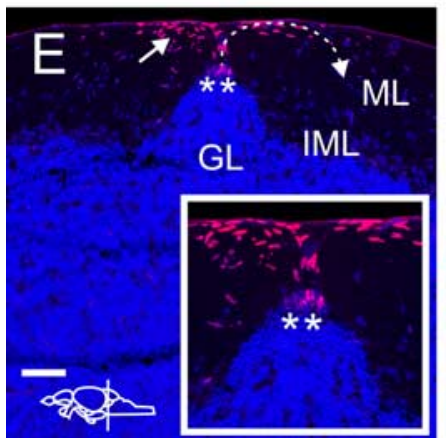

BrdU 4h BLBP GFAP

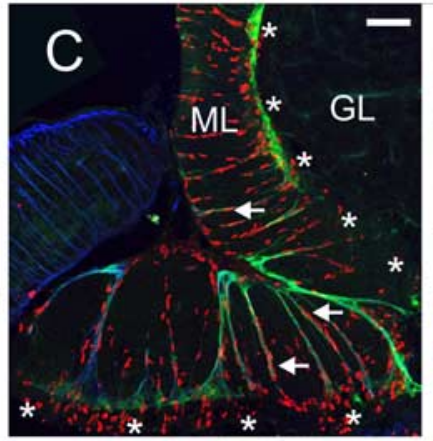

BrdU 6d PCNA

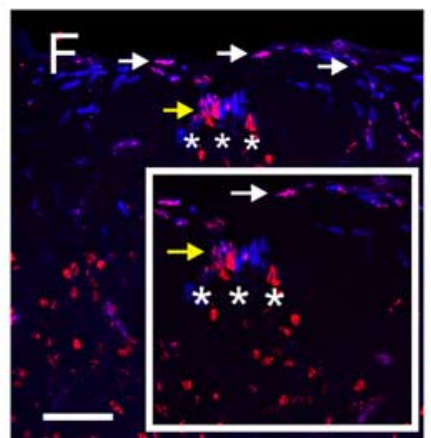

BrdU 6d PCNA

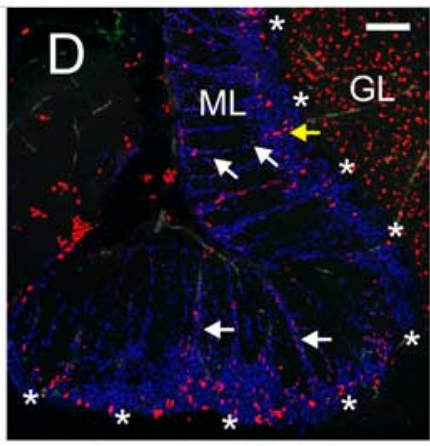

BrdU 6w PCNA

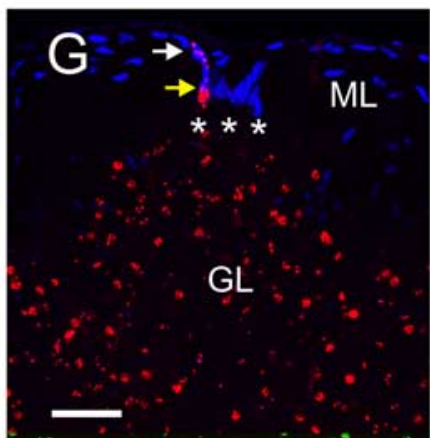

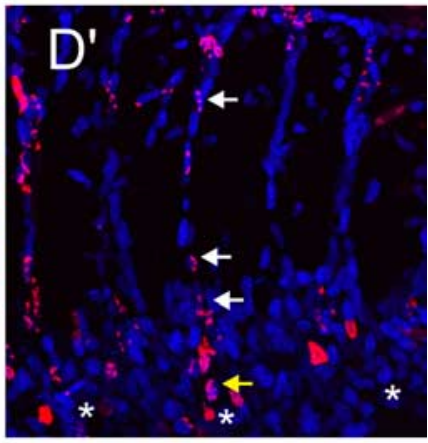

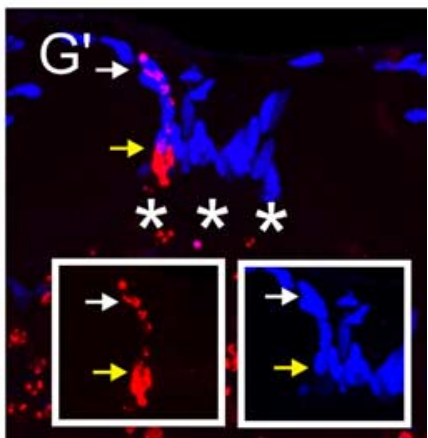

Figure 1. A, In the CNS of adult mammals, stem cell niches are restricted to the subventricular zone (SVZ) and the dentate gyrus (DG) in the telencephalon. In zebrafish, stem cell niches are more abundant and distributed along the entire rostrocaudal brain axis. A population of label-retaining progenitors is confined to a distinct location in the dorsomedial cerebellum. $\boldsymbol{B}-\mathbf{G}$, Confocal images of parasagittal sections through the cerebellum of adult zebrafish. $\boldsymbol{B}$, Overview of the proliferation pattern in the cerebellum. $\mathrm{BrdU}(2 \mathrm{~d})$ and PCNA staining show proliferating cells along the midline and the interface between ML and GL $\left(^{*}\right)$. The proliferating cells form radial spokes that emanate from the interface between the ML and GL. General morphology is visualized with fluorescent nissl staining (gray). C, A short pulse of BrdU (4 h) labels chains of proliferating progenitors in the ML. BrdU + cells migrate along glial scaffolds (white arrows). D, A pulse of BrdU ( $1 \mathrm{~d}$ ) followed by increasing chase times shows that BrdU is increasingly diluted out in the chains of BrdU + cells (white arrows) and accumulates in the GL (see supplemental Fig. $52 A$, available at www.jneurosci.org as supplemental material). Cells in the interface between the ML and GL retain the BrdU label (yellow arrow). $\boldsymbol{E}-\mathbf{G}$, (ross sections through the cerebellum of adult zebrafish. $\boldsymbol{E}, \mathrm{PCNA}+$ proliferating cells are confined to the midline and interface between the ML and GL in the dorsal cerebellum $\left({ }^{*}\right)$. Proliferating cells emanate out in a fountain shape from the midline (white arrow). $\boldsymbol{F}$, After a pulse of BrdU ( 1 d) followed by a $6 \mathrm{~d}$ chase, most BrdU + cells have migrated away. Label-retaining PCNA/BrdU + cells are found at the midline (yellow arrow). More diluted BrdU-labeled PCNA + cells are found lateral to the midline (white arrows). $\mathbf{G}, \mathbf{G}^{\prime}$, A long pulse of $\mathrm{BrdU}(2 \mathrm{~d}$ ) followed by 6 weeks chase shows a label retaining cell (yellow arrow) giving rise to weakly BrdU-labeled cells (white arrow). *Progenitor niche; GL, granule cell layer; IML, intermediate layer; ML, molecular layer. Scale bars: $A, 100 \mu \mathrm{m} ; \mathrm{C}-\boldsymbol{E}, 50 \mu \mathrm{m} ; \boldsymbol{F}-\mathbf{G}, 10 \mu \mathrm{m}$.

BrdU-labeled clones of migrating cells were detected emanating from the proliferating cells in the cap (Fig. $1 C, D, F, G$ ). Regardless of the BrdU pulse length ( $4 \mathrm{~h}-2 \mathrm{~d}$ continuous labeling), only a few label-retaining cells remained in the cap after 1 week of chase time (Fig. 1D, G). After 4-6 weeks chase time, few BrdU-positive cells were found in the cap (8.3 cells, SEM 2.29, $n=6$ ) (Fig. 1G; supplemental Fig. S2 J, K, available at www.jneurosci.org as supplemental material). This data show that adult cerebellar stem cells are confined to a distinct zone in the dorsal cerebellum (summarized in Fig. 5).

Adult cerebellar progenitors express neural stem cell markers Next, we studied the expression of canonical neural stem cell markers in the cerebellar progenitors. The intermediate filament Nestin is a widely used marker for neural stem cells and is strongly expressed by mammalian cerebellar progenitors (Lendahl et al., 1990; Wang and Zoghbi, 2001). We created a transgenic zebrafish line $\mathrm{Tg}$ (nestin:GFP) using BAC recombineering technology. In this transgenic line, GFP expression is driven by nestin regulatory elements and recapitulates reported nestin mRNA expression (data not shown) (Mahler and Driever, 2007). In the adult zebrafish cerebellum, Nestin:GFP was expressed in proliferating and migrating cells (Fig. $2 A-C$; supplemental Figs. S3E, S4, available at www.jneurosci.org as supplemental material). It was also expressed transiently in S100 $\beta$-positive glia (Fig. 2 B; supplemental Fig. $\mathrm{S} 4 B, D$, available at www.jneurosci.org as supplemental material). Label retaining Nestin:GFP + cells were found in the stem cell niche (Fig. 2C). SoxB transcription factors and the RNA binding protein Musashi have been reported to be expressed in embryonic and adult neural stem cells (Kaneko et al., 2000; Graham et al., 2003). In the adult zebrafish cerebellum, Sox2 was expressed in Purkinje neurons, glia, and in a subset of the proliferating cells (Fig. 2D; supplemental Fig. S2 B,C, available at www.jneurosci.org as supplemental material). Musashil was ex- 
Nestin:GFP PCNA

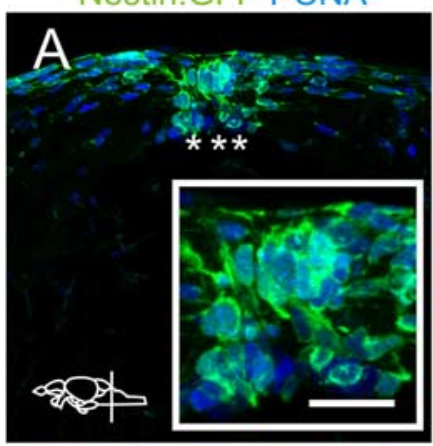

Meis Nestin:GFP Sox2

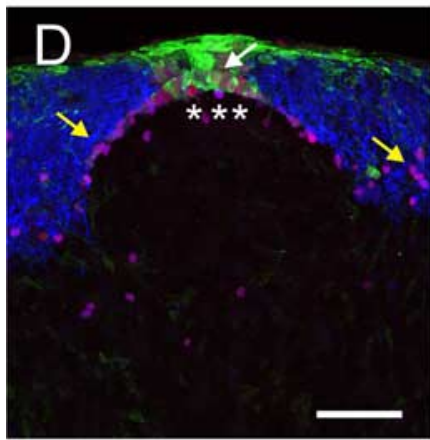

Meis Musashi1 PCNA

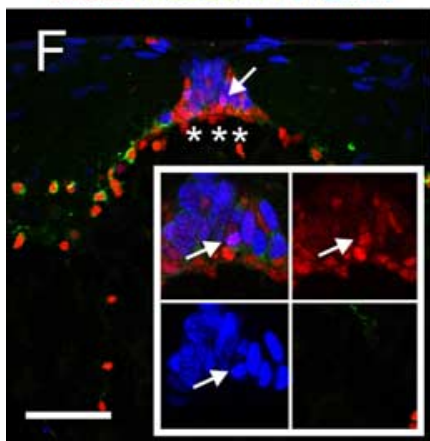

S100 $\beta$ Nestin:GFP PCNA
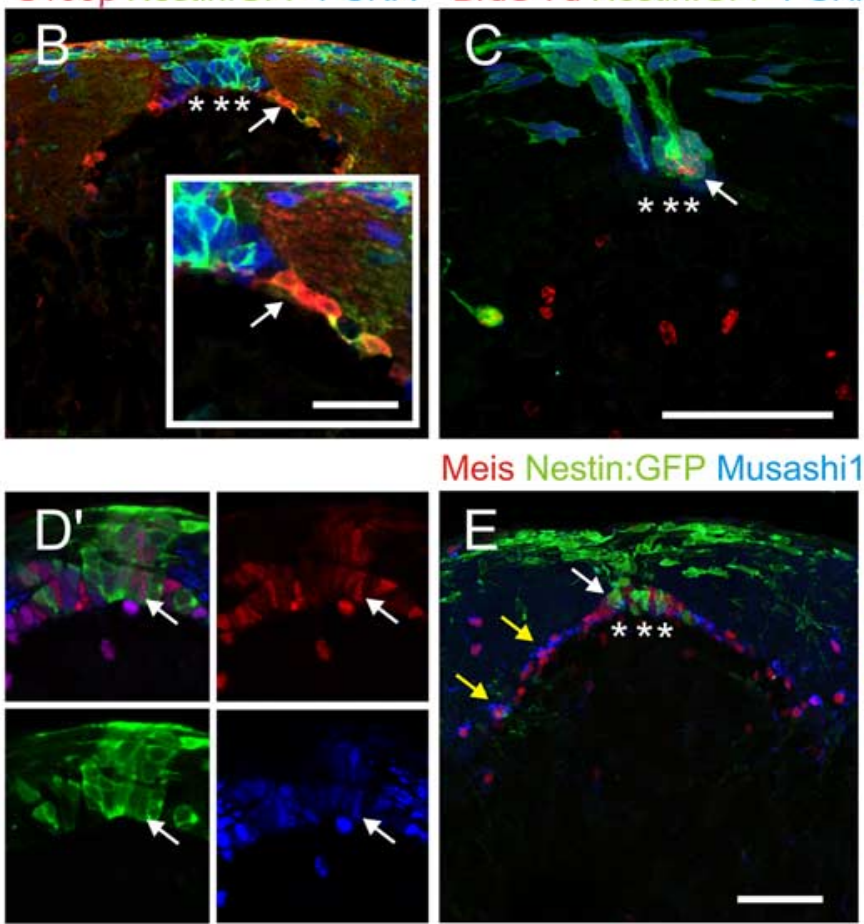

PCNA ZO-1 S100B

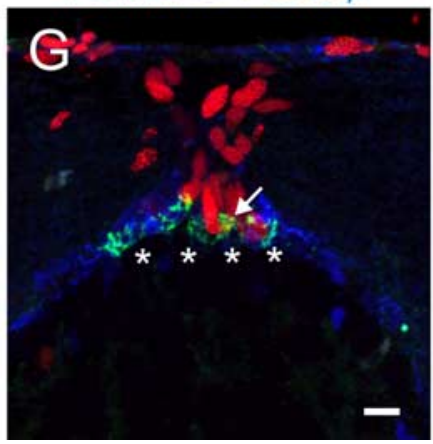

Meis Nestin:GFP Musashi1

BrdU 7d Nestin:GFP PCNA
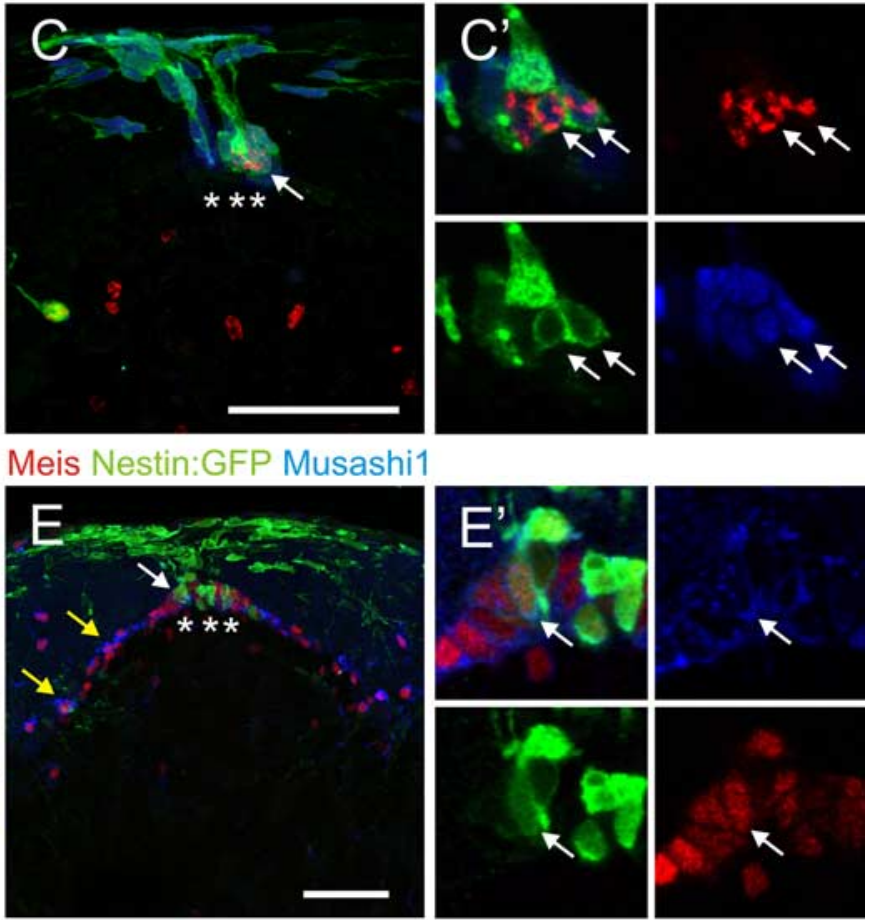

Nestin:GFP PCNA ZO-1
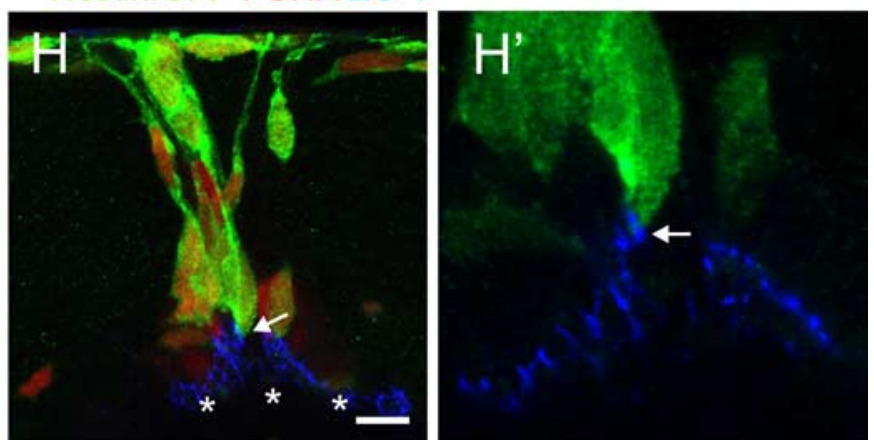

Figure 2. Adult cerebellar progenitors express stem cell markers. $\boldsymbol{A}-\boldsymbol{I}$, Confocal images of cross-sections through the adult zebrafish cerebellum. $\boldsymbol{A}$, Nestin:GFP + cells colabel with PCNA. $\boldsymbol{B}$, Lateral to the proliferating cells, Nestin:GFP colabels with S100 $\beta+$ cells (arrow).C, A pulse of BrdU ( $1 \mathrm{~d}$ ) followed by $7 \mathrm{~d}$ chase time shows that Nestin:GFP + cells are label retaining (BrdU/PCNA + ). $\boldsymbol{D}$, Meis + and Sox ${ }^{2+}$ glia are found in the IML, ML (yellow arrows) and stem cell niche. Meis and Sox2 colocalize with a subset of Nestin:GFP + cells (white arrow). $E$, Musashi + and Meis + glia are found in the IML, ML and stem cell niche (yellow arrows). Musashi and Meis colocalize with a subset of Nestin:GFP+ cells (white arrow). $\boldsymbol{F}$, Meis colocalizes with a subset of the PCNA + cells (arrow). G, $\boldsymbol{H}$, The stem cell niche is distinctly marked by cell polarity markers. $\mathbf{G}$, Proliferating PCNA + cells are labeled with Z0-1 apically (arrow). The stem cell niche is distinctly marked by Z0-1+ staining. $\boldsymbol{H}$, A high-magnification image of a proliferating polarized Nestin:GFP + cell (white arrow). $\boldsymbol{H}^{\prime}$, The apical side of the Nestin:GFP + cell is labeled with Z0-1 (white arrow). *Progenitor niche; IML, intermediate layer; ML, molecular layer. Scale bars: $\boldsymbol{A}-\boldsymbol{F}, 50 \mu \mathrm{m} ; \boldsymbol{G}, \boldsymbol{H}, 10 \mu \mathrm{m}$.

pressed in glia and in a subset of the proliferating cells (Fig. $2 E, F)$. During development Meis proteins are potent regulators of cell proliferation and suppress differentiation. In the cerebellum Meis 1 has been identified in proliferating progenitors in the ventricular zone (VZ) and granule cell progenitors in the EGL (Morales and Hatten 2006). By using an antibody recognizing Meis proteins we found that Meis is expressed in a subset of the proliferating progenitors, glia and Purkinje neurons (Fig. 2E,F; supplemental Fig. S2C, $D$, available at www.jneurosci.org as supplemental material). In sum, our data demonstrate that adult cerebellar progenitors maintain expression of the stem cell and progenitor markers Nestin, Sox2, Meis, and Musashi1. Nestin is expressed by most, if not all, cycling cerebellar progenitors whereas Sox2, Musashil and Meis are found in supportive glia and a subset of the proliferating progenitors.
Cerebellar stem cells maintain apical-basal polarity and are distinctly demarcated by adherens junctions

In mammals, neural progenitors display neuroepithelial properties, such as expression of the intermediate filament Nestin, and maintain apical-basal polarity features such as the apical localization of centrosomes and adherens junctions (Götz and Huttner, 2005). We found that the zebrafish cerebellar stem cell population is distinctly demarcated by adherens junctions and expresses canonical apical markers such as zona occludens protein 1 (ZO1), $\beta$-catenin, $\gamma$-tubulin, and aPKC (Fig. $2 G, H$; supplemental Fig. S2 $E, G$, available at www.jneurosci.org as supplemental material). Analysis of nestin:GFP expressing progenitors show that they are distinctly polarized (Fig. $2 H$ ). Most of the detected mitotic divisions of nestin:GFP + cells were horizontal $(n=7,54$ / 57) but also divisions along the apical-basal axis were found (3/ 


\section{S100ß 3CB2 Vimentin}

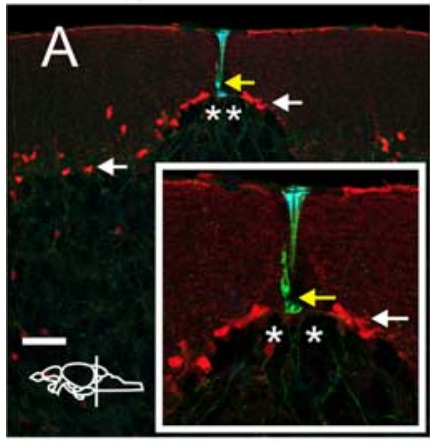

BrdU 1d S100ß

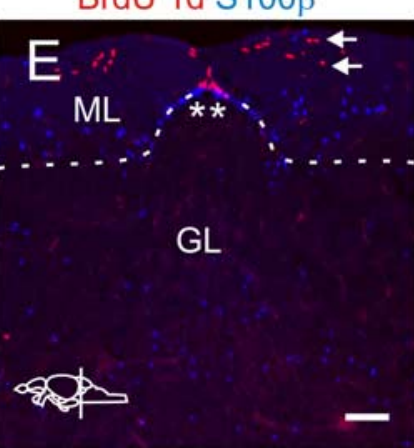

GFAP BLBP

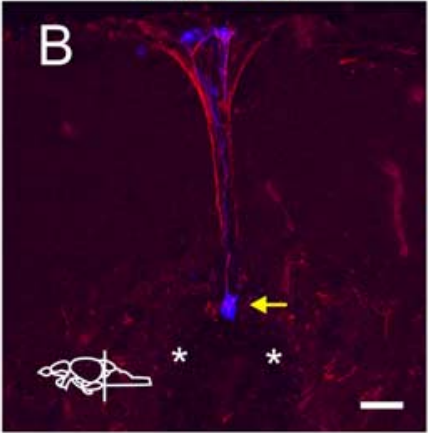

BrdU 3d HU S100ß

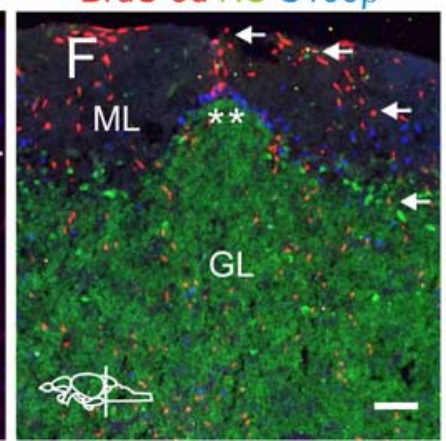

BrdU 4h BLBP GFAP

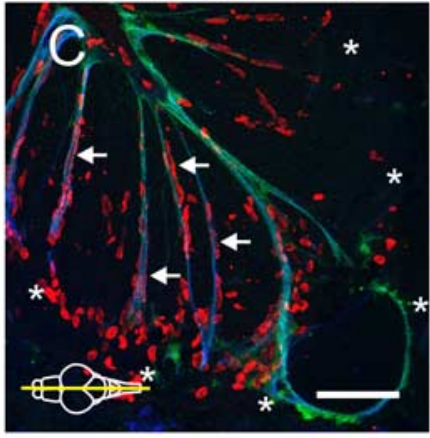

BrdU 6d pH3 PCNA

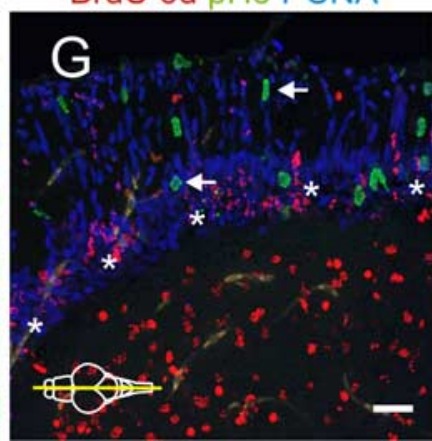

BrdU 2d PCNA Nissl

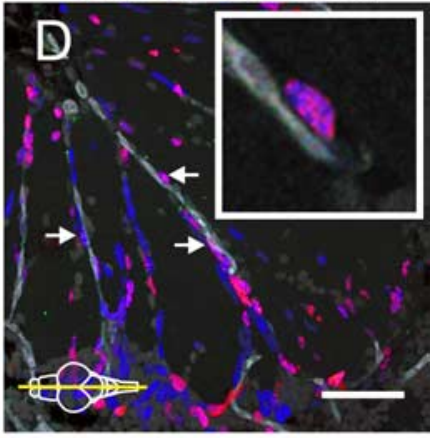

HU-C/D BrdU 1d

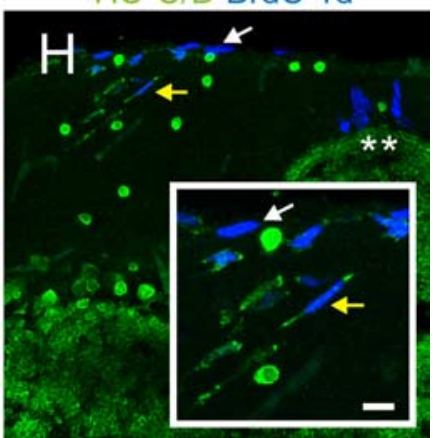

Figure 3. Different populations of glia serve as scaffold and support in the cerebellar stem cell niche. $\boldsymbol{A}, \boldsymbol{B}$, Two different populations of glia are detected in the zebrafish cerebellum. $S 100 \beta+$ cells are found in the IML (white arrows). A few vimentin/3CB2/BLBP + cells with a distinct radial morphology are found at the midline (yellow arrow). Proliferating cells migrate rapidly out from the stem cell niche along the glial scaffolds. C, BrdU + cells migrating along GFAP/BLBP + radial processes (arrows). D, BrdU/PCNA + cells are found in close proximity to blood vessels (arrows). The proliferating granule precursors migrate rapidly into the GL. $\boldsymbol{E}$, After a short BrdU pulse $(4 \mathrm{~h}$ ) and chase ( $1 \mathrm{~d})$, BrdU + cells are still confined to the $\mathrm{ML}$ (arrows). $\boldsymbol{F}, \mathrm{After}$ a $3 \mathrm{~d}$ chase, BrdU + cells can be traced from the stem cell niche $\left(^{*}\right)$ to the $\mathrm{GL}$ (arrows). G, pH3 + cells (arrows) distributed along the dorsoventral axis of the ML show that the migrating cells can proliferate during the course of migration (parasagittal section). $\boldsymbol{H}$, Migrating cells start expressing the neuronal transcription factor HU-C/D during the course of migration. Cells closer to the stem cell niche ${ }^{*}$ ) are not $H U-C / D+$ (white arrows) whereas cells more lateral express HU-C/D (yellow arrows). *Progenitor niche; IML, intermediate layer; ML, molecular layer; GL, granule cell layer. Scale bars: $\boldsymbol{A}, \mathbf{C}-\boldsymbol{F}, 50$ $\mu \mathrm{m} ; \boldsymbol{B}, \mathbf{G}-\boldsymbol{I}$, $10 \mu \mathrm{m}$.

57) (supplemental Fig. S2 H, I, available at www.jneurosci.org as supplemental material). Thus, the stem cells reside in a specialized niche (summarized in Fig. 5) consisting of a small pool of highly polarized cells that are demarcated by apical markers.

\section{Different populations of glia serve as scaffolds and support in the cerebellar stem cell niche}

During neural development and in the adult CNS of mammals and birds, cells with astroglial characteristics (radial glia) act as neural progenitors as well as scaffolds for cell migration (Doetsch and Scharff, 2001; Alvarez-Buylla and Lim, 2004). Two distinct populations of glia were found in the adult zebrafish cerebellum. One small population of glia with typical radial glial morphology was restricted to the very medial part of the stem cell niche (Fig. $3 A$ ). These cells are immunopositive for GFAP, vimentin, BLBP and $3 \mathrm{CB} 2$, but not $\mathrm{S} 100 \beta$ (Fig. $3 A, B$; supplemental Fig. S2 J, K, available at www.jneurosci.org as supplemental material). Surprisingly, the GFAP/vimentin/BLBP+ radial glia did not show colocalization with proliferation markers $(n=5)$ (Fig. $3 C$; supplemental Figs. S2 J, O, S4D, E, available at www.jneurosci.org as supplemental material). However, the radial processes from this distinct cell population appeared to function as scaffolds during the initial dorsal migration phase. A short pulse of BrdU or PCNA staining revealed migration of proliferating cells along GFAP/ $\mathrm{BLBP} /$ vimentin immunopositive radial processes (Figs. $1 C, 3 C$; supplemental Fig. S2 J, available at www.jneurosci.org as supplemental material). Migrating cells were also found in close proximity to blood vessels and seemed to use them as scaffolds (Fig.
3D; supplemental Fig. S3C, available at www.jneurosci.org as supplemental material). Another population of glia that was strongly $\mathrm{S} 100 \beta+$ but weakly vimentin $/ 3 \mathrm{CB}^{2+}$ was found interspersed between the molecular and granular cell layer (Fig. $3 A$ ). This population showed gfap:GFP expression but did not stain with GFAP antibodies (supplemental Fig. S2 I, available at www. jneurosci.org as supplemental material) and had less pronounced radial glia morphology (Fig. $3 A$ ). The $S 100 \beta$ glia bordered the proliferating cells laterally (Figs. $2 B, 3 E$ ). Nestin:GFP was transiently detected in $\mathrm{S} 100 \beta$ glia in close proximity to the progenitors (Fig. $2 B$; supplemental Fig. $\mathrm{S} 4 B, D$, available at www.jneurosci.org as supplemental material). These results show that the proliferating cerebellar cells do not express canonical radial glial or astroglial markers, such as BLBP, GFAP, vimentin and S100 $\beta$. However, two populations of distinct glia are associated with the cerebellar stem cell niche (summarized in Fig. 5).

\section{Rapid proliferation and chain migration of granule cell} precursors along radial glia and blood vessels

The majority of cells migrated rapidly out of the stem cell niche into the granule cell layer. A short BrdU pulse $(4 \mathrm{~h})$ followed by a short chase time $(0-24 \mathrm{~h})$ showed that the majority of proliferating cells were still confined to the molecular layer (Fig. 3E; supplemental Fig. S3A, available at www.jneurosci.org as supplemental material). In contrast, a short BrdU pulse $(4 \mathrm{~h})$ followed by intermediate chase times ( $3 \mathrm{~d}$ ) labeled cells already present in the granular cell layer (Fig. $3 F$; supplemental Fig. S3A, available at www.jneurosci.org as supplemental material). After a $6 \mathrm{~d}$ chase 
PCNA BrdU 6w Nissl

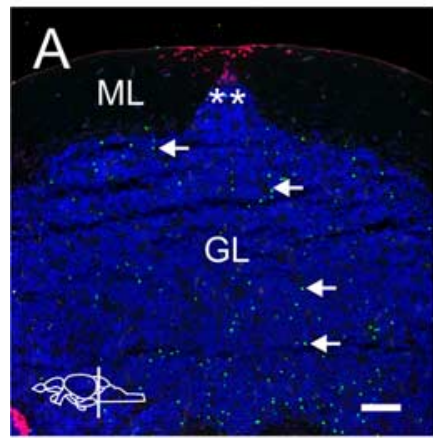

Nestin:GFP Neurod

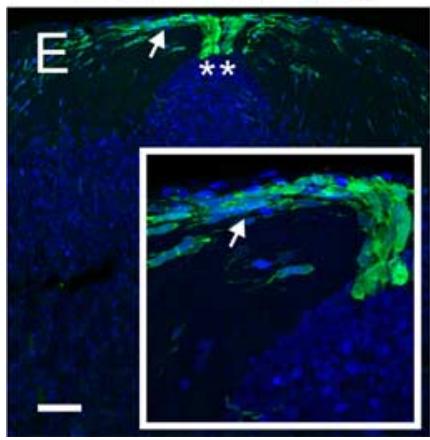

BrdU 6w S100B PCNA

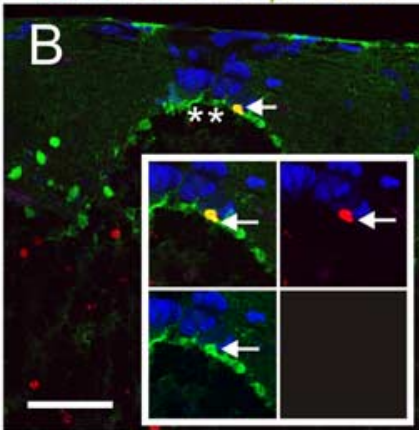

Nestin:GFP Pax6

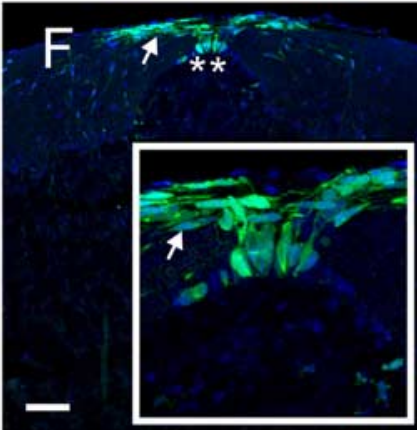

zic 1

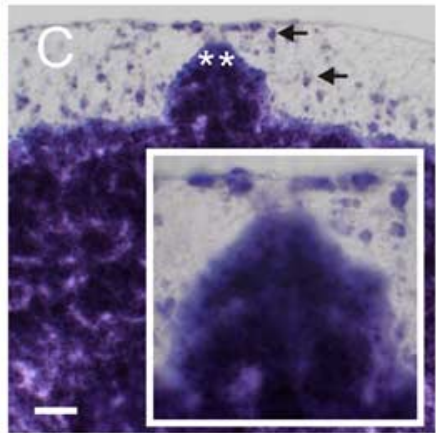

Nestin:GFP GAP-43

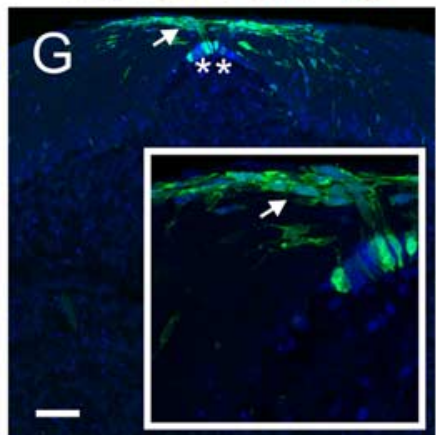

zic 3

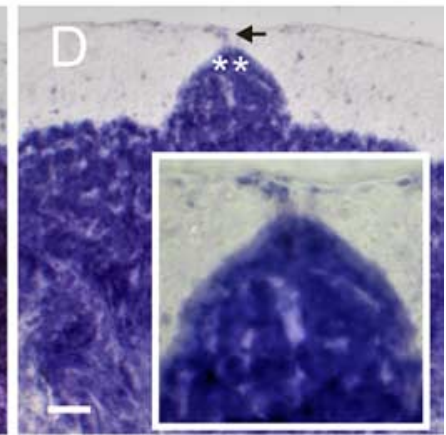

Parvalb Pax2 Nissl

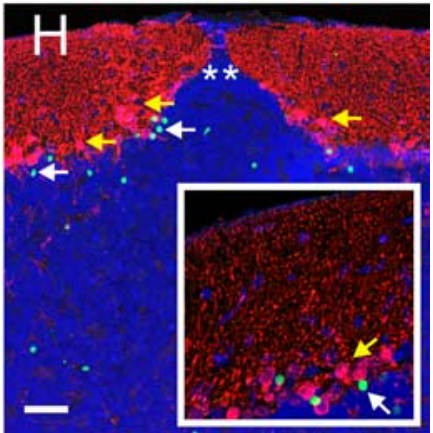

Figure 4. Granule cells and a small number glia are generated in the adult zebrafish cerebellum. $A$, After a long BrdU pulse ( $2 \mathrm{~d})$ and chase ( 6 weeks), virtually all BrdU + cells are confined to the $\mathrm{GL}$ (arrows). B, A BrdU/S100 $\beta+$ and PCNA - cell after 6 weeks of chase time shows that a low number of glia is generated. RL and granule cell markers are expressed in the stem cell niche. $\boldsymbol{C}, \boldsymbol{D}$, Expression of zic 1 and zic 3 in the adult cerebellum. Both genes are expressed in the stem cell niche, migrating cells (arrows) and cells in the GL.E, Migrating granule precursors are Neurod + (arrows). F, Nestin:GFP + progenitors, migrating cells and granule neurons are Pax6 + (arrows). G, Migrating granule precursors are highly GAP-43+ whereas cells in the stem cell niche and GL display lower levels of immunoreactivity. $\boldsymbol{H}, \mathrm{Pax}^{2+}$ cells (white arrows) are found in the IML among parvalbumin + Purkinje cells (yellow arrows). ${ }^{*}$ Progenitor niche; $\mathrm{GL}$, granule cell layer; IML, intermediate layer; ML, molecular layer. Scale bars: $\boldsymbol{A}-\boldsymbol{H}, 50 \mu \mathrm{m}$.
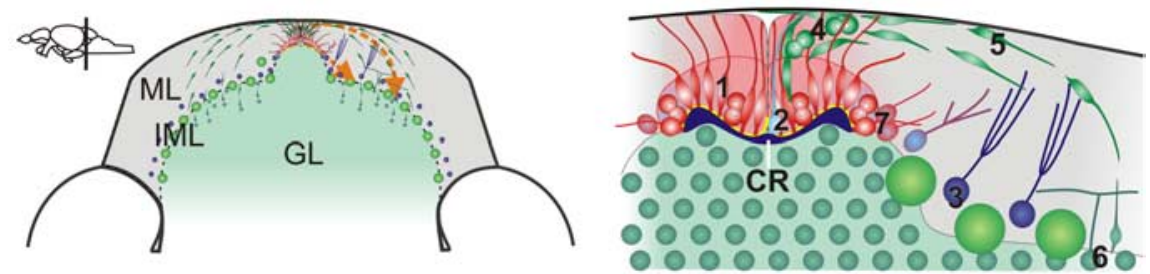

Figure 5. Schematic summary of the adult cerebellar stem cell niche. 1, Polarized progenitors (red) with adherens junctions are restricted to the midline of the dorsal cerebellum (yellow line). 2-3, The progenitors are flanked medially and laterally by two populations of nonproliferating glia. 2, A few glia with a radial morphology (light blue) are found close to the midline. 3, Bergmann glia-like cells are interspersed in the IML (dark blue). 4, The progenitors give rise to rapidly migrating granule precursors (dark green) that initially migrate dorsolaterally. During this initial phase, the granule precursors still proliferate. 5, After reaching the meninge, the granule precursors change to a unipolar morphology and start to migrate ventrolaterally to the GL. 6, Granule precursors migrate into the GL. 7, Bergmann glia-like cells are generated from the lateral portion of the stem cell niche. $C R$, Cerebellar recessus; GL, granule cell layer; IML, intermediate layer; ML, molecular layer.

period, the vast majority of cells $(>95 \%)$ were confined to the granular cell layer (Fig. 1D). A combination of BrdU, PCNA, and pH3 staining showed that the cells still proliferate throughout migration (Fig. 3D, G; supplemental Fig. S3A,B, available at www.jneurosci.org as supplemental material). Initially, most of the generated cells migrated dorsally along glial processes (Fig. 3C,D) until altering course laterally just before reaching the dorsal surface (Figs. $1 F, 3 E$ ). After $\sim 80 \mu \mathrm{m}$ of lateral movement, the majority of cells migrated ventrally toward the granule cell layer (Fig. $3 F$ ). As the cells migrated ventrolaterally, their morphology changed from a prolonged ovoid shape to a unipolar spindle shape typical of migrating granule precursors (Fig. $3 H$; supplemental Fig. S3D,E, available at www.jneurosci.org as supplemental material). These spindleshaped cells emitted processes and expressed the early neuronal marker HUC/D (Fig. $3 H$; supplemental Fig. S3 $A, D$, available at www.jneurosci.org as supplemental material). Furthermore, they expressed other neurogenic factors and proteins characteristic of differentiating granule cells, including GAP-43 and Neu$\operatorname{rod}$ (Fig. $4 E, G$ ). However, a few cells were displaced laterally from the stem cell niche and later differentiated into glia (Figs. $2 B$, $4 B$; supplemental Fig. $\mathrm{S} 4 A, B$, available at www.jneurosci.org as supplemental material). This data show that most cells quickly migrate out from the stem cell niche into the granule cell layer (summarized in Fig. 5). During migration, the neuroblasts express granule cell markers and use both radial and tangential migration. In contrast, cells that are displaced laterally from the stem cell niche turn into glia.

\section{Generation of granule cells and a small number of glia}

During development, different cerebellar cell types are produced in a strict temporal order from increasingly committed progenitors. To learn about the potential of adult cerebellar stem cells in zebrafish, we examined which cell types are generated in vivo. To examine the fate of the generated cells, extended BrdU pulses (2 d) and long chase experiments (4-6 weeks) were analyzed in combination with neuronal markers. Antibodies against Parval- 
bumin and Calretinin were used to detect Purkinje and eudendroid neurons in combination with fluorescent Nissl staining. Small sized BrdU/Nissl double-positive cells were abundant in the granule cell layer, showing that mainly granule cells are generated (Fig. 4A). This is in agreement with our previous study where BrdU and the neuronal marker $\mathrm{HU}-\mathrm{C} / \mathrm{D}$ colocalized in granule neurons (Grandel et al., 2006). Only a few cells remained in the molecular or intermediate layer after 4-6 weeks chase time (3.33 cells, SEM $0.49, n=6$ ). None of them colocalized with the markers or showed morphological characteristics of Purkinje or eudendroid cells. However, a low amount of BrdU/S100 $\beta$ positive glia ( 0.83 cells, SEM $0.31, n=6)$ were found in the intermediate layer lateral to the proliferating progenitor population (Fig. $4 B$ ). No BrdU/BLBP-positive radial glia were detected after a long BrdU chase $(n=3)$. Together, these results demonstrate that the vast majority of cells generated by the adult zebrafish cerebellar niche are granule neurons and only a small number are glia.

\section{The adult cerebellar stem cell niche expresses rhombic lip and granule cell markers}

During early vertebrate development, cerebellar neurons and glia originate from two principal germinal zones, the rhombic lip (RL) and the VZ. Excitatory granule neurons and unipolar brush cells are generated by the RL, whereas Purkinje cells, glia, and inhibitory neurons are generated from the VZ (Wingate, 2005). We found that both neurons and glia are continuously generated in the adult zebrafish cerebellum. Thus, we next wanted to know whether the adult progenitors express canonical cerebellar RL or VZ markers.

We first examined well known markers expressed early in granule progenitors, including atoh1, zic1, zic3, pax6, and meis1 (Ben-Arie et al., 1997; Nagai et al., 1997; Engelkamp et al., 1999; Morales and Hatten, 2006). The atonall orthologues atoh $1 a-b$ are not expressed in the adult zebrafish cerebellum (data not shown). However, the early granule cell progenitor markers zic1, zic3 and Pax6 are highly expressed in the stem cell niche and in both migrating and granule cells (Fig. 4C-F; supplemental Fig. S3F, available at www.jneurosci.org as supplemental material).

During later stages of granule cell development in vertebrates, Neurod is expressed in migrating, differentiating, and mature granule cells (Miyata et al., 1999; Mueller and Wullimann, 2002). In the adult zebrafish, Neurod is strongly expressed in the migrating cells and mature granule neurons (Fig. $4 E$; supplemental Fig. S3G, available at www.jneurosci.org as supplemental material). reelin is expressed in migrating granule cells during vertebrate development and in granule cells within the adult cerebellum (Pesold et al., 1998; Costagli et al., 2002). In the adult zebrafish cerebellum, reelin expression was confined to the mature granule cells (supplemental Fig. S3H, available at www.jneurosci.org as supplemental material). Growth associated protein 43 (GAP-43) is expressed in differentiating neurons and cerebellar precursors (Console-Bram et al., 1996). In the adult zebrafish, GAP-43 staining was seen in proliferating migrating cells and in the granule cells (Fig. 4G; supplemental Fig. S3I, available at www. jneurosci.org as supplemental material).

RL progenitors are the last cerebellar progenitor types generated. Therefore, we examined whether markers for earlier progenitors, i.e., cerebellar VZ progenitors, persisted into adulthood in the cerebellar progenitors. In mouse, the transcription factor Ptfla marks progenitors of cerebellar inhibitory neurons in the VZ (Hoshino et al., 2005). ptfla expression was absent in the adult zebrafish cerebellum (data not shown). In rodents, Pax2 identifies precursors of inhibitory neurons during cerebellar de- velopment and is later confined to Golgi neurons (Maricich and Herrup, 1999). In the adult zebrafish, Pax2-positive cells were dispersed in the intermediate cell layer (Fig. $4 H$ ). These cells are presumably mature Golgi cells since Parvalbumin (a marker of mature basket, stellate and Purkinje cells) did not colocalize with Pax2 (Fig. $4 H$ ).

Consistent with the notion that primarily granule neurons are generated, our results show that early RL and granule precursor markers, such as Pax6, Meis1, zic1, and zic3, are expressed in the adult stem cell niche. Furthermore, markers of differentiating and maturating granule neurons, such as GAP-43 and Neurod, are expressed in migrating granule cells in zebrafish. Importantly, the VZ progenitor markers ptf1a and Pax2 are not found in the adult stem cell niche.

\section{The adult cerebellar stem cell niche is derived from displacement of the IVth ventricle and rhombic lip progenitors}

So far, very little is known about how adult neural stem cell niches are created during development, and how they are maintained postembryonically. In rodents it has been proposed that a key feature of neural progenitors is the retention of direct contact with a ventricle. Cerebellar progenitors in the adult zebrafish are located very far from all known ventricles, so we hypothesized that adult cerebellar progenitors could derive from progenitors that were ventricularly located in the embryo. To dynamically trace the origin and organization of the adult cerebellar stem cell niche, we used in vivo imaging, ventricular dye injections, and analysis of key markers in embryonic and juvenile zebrafish.

We found that progenitors derive from the anterior RL and that the stem cell niche is created in two steps. The initial step is a morphogenetic process that takes place during embryonic and early juvenile stages ( $24 \mathrm{hpf}-5 \mathrm{dpf}$ ). Similar to other vertebrates, there is a general morphogenetic $90^{\circ}$ rotation of rhombomere 1 including the RL (Fig. 6A, B, movie 1) (Sgaier et al., 2005). In addition, medially located RL progenitors and a small part of the IVth ventricle shift rostrally to form a dorsomedial extension of the IVth ventricle (Fig. 6A, B; supplemental Fig. S5, available at www.jneurosci.org as supplemental material). This ventricular extension forms a distinct recessus from $5 \mathrm{dpf}$ onwards (Fig. $6 B, C$, animations 2-4; supplemental Fig. S5, available at www. jneurosci.org as supplemental material). This extension of the IVth ventricle was previously unknown in teleosts, and we thus name it the cerebellar recessus (CR). The second step involves displacement of the progenitors and CR through tissue growth taking place from juvenile $(5 \mathrm{~d})$ to adult stages. During the growth of the cerebellum, newly generated granule neurons expand the granule layer, which in turn gradually separates the progenitors and CR from the IV th ventricle (Fig. 8 B). At the same time, the stem cell niche is displaced ventrally from the roof plate because of molecular layer expansion resulting from the addition of new axons from the newly generated granule neurons (Fig. $8 B$ ). The observed displacement of the cerebellar stem cell niche suggests that even at its deep location the niche retains ventricular contact. Indeed, filling the IIIrd and IVth ventricle by dye injections in juvenile and adult fish showed that the CR still remains in contact with both ventricles (Fig. 6B, animations 2-4; supplemental Fig. S5, available at www.jneurosci.org as supplemental material).

In summary, our analysis of the origin of the cerebellar stem cell niche shows that it is generated in two steps: (1) initial morphogenetic movements, and (2) subsequent tissue growth (summarized in Fig. 8A, B). As a result, ventricularly located RL pro- 

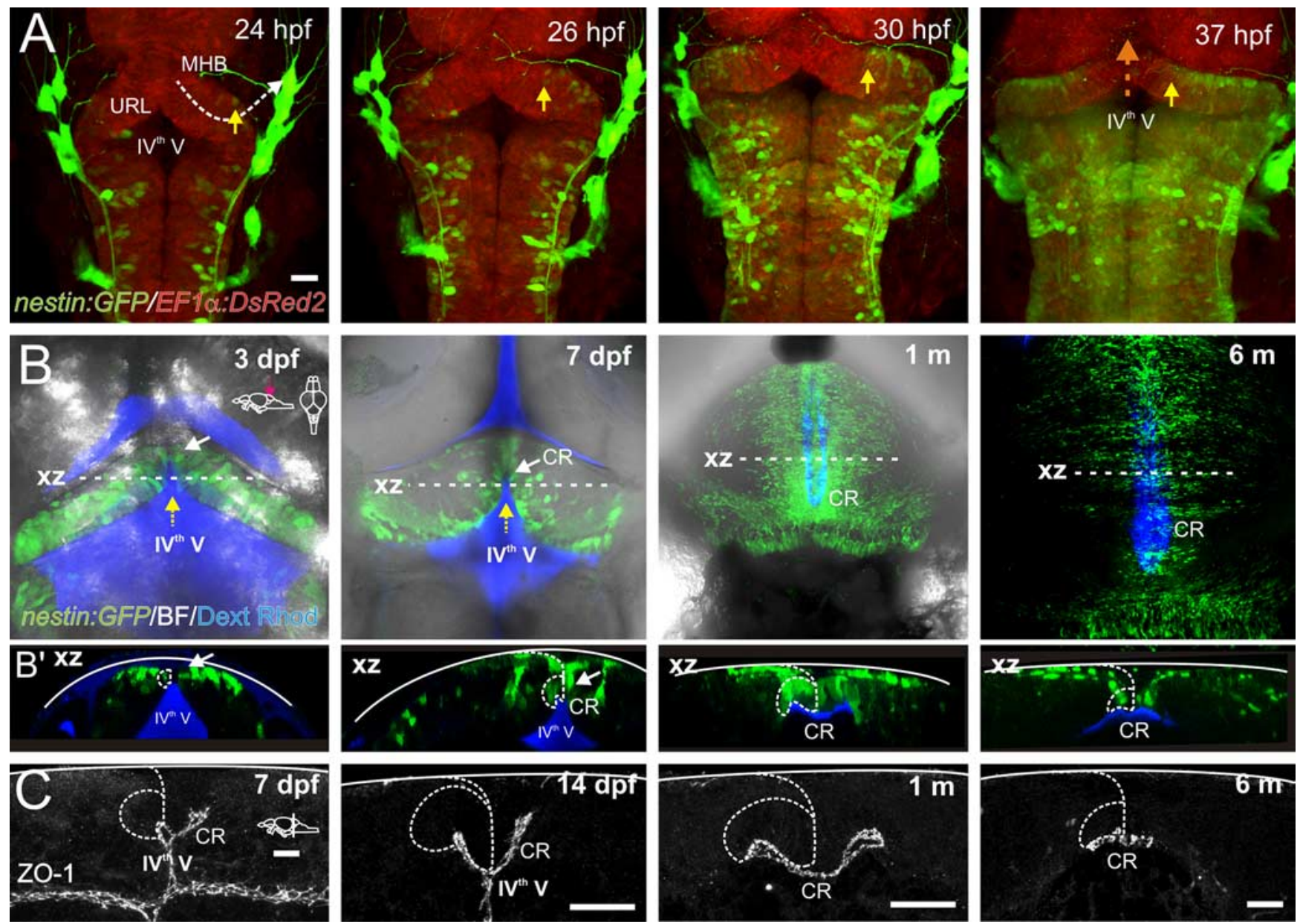

Figure 6. The adult cerebellar stem cell niche is derived from ventricular RL progenitors. $\boldsymbol{A}, \boldsymbol{B}$, In vivo imaging from the dorsal view of the cerebellum at different ages (anterior is up). $\boldsymbol{A}$, Morphogenetic rotation of rhombomere 1 and the cerebellar primordium (white arrow). nestin:GFP + cerebellar progenitors gradually migrate medially toward the midline (yellow arrows). At approximately $36 \mathrm{hpf}$, the dorsal portion of the IVth ventricle starts to shift rostrally (orange arrow). EF1 $\alpha$ :DsRed 2 labels all cells in the neural tube. $\boldsymbol{B}$, Development of the stem cell niche and the CR and their proximity to the IVth ventricle. Live imaging of nestin:GFP + cells and the IVth ventricle. The IVth ventricle is filled with rhodamine dextran. At 3 dpf nestin:GFP + progenitors have migrated to the midline (white arrow). The dorsomedial portion of the IVth ventricle (CR) continues to gradually shift rostrally (yellow arrows). At 7 dpf the nestin:GFP+ progenitors are found medially at the IVth ventricle (white arrow) and the basic layout of the niche is seen. In juvenile $(1 \mathrm{~m})$ and adult fish $(6 \mathrm{~m})$, the CR has been displaced from the rest of the IVth ventricle through tissue growth. The CR is seen as blue at the midline. The layout of the stem cell niche and the proximity of nestin:GFP + progenitors to the CR is clearly seen in the cross-sections. C, Development of the CR and stem cell niche visualized with Z0-1 immunostaining. At $7 \mathrm{dpf}$ the dorsomedial part of the IVth ventricle forms a small recessus. At $14 \mathrm{dpf}$ the granule cell layer is still relatively small and the recessus is in contact with the rest of the IVth ventricle. From $1 \mathrm{~m}$ and onwards, only the recessus is visible in the corpus cerebelli. The stem cell niche is outlined. IVth V, IVth ventricle; $(\mathrm{R}$, cerebellar recessus; $\mathrm{MHB}$, mid hindbrain boundary; URL, upper rhombic lip. Scale bars: C, $25 \mu \mathrm{m}$.

genitors and a small portion of the IVth ventricle, the cerebellar recessus, are pinched off and displaced deep into the tissue.

Fibroblast growth factors regulate stem cell activity in the adult cerebellum

Signals propagated through the CSF in the ventricle are thought to be important regulators of stem cell activity. Growth factors such as fibroblast growth factors are found in the CSF (Johanson et al., 2008). Furthermore, Fgf signaling is crucial for midbrain and cerebellar development in vertebrates (Rhinn et al., 2006; Partanen, 2007). To test the requirements of Fgf signaling on the adult cerebellar stem cells niche, we used transgenic zebrafish with a temperature inducible dominant-negative $\operatorname{Fgfr}(h s p 70: d n$ $f g f r 1)$. A single heat shock uniformly induces dn-fgfr 1 transgene expression and efficiently blocks Fgf signaling for at least $1 \mathrm{~d}$ (Lee et al., 2005). $h s p 70: d n-f g f r 1$ fish and control fish were heat induced once, and $24 \mathrm{~h}$ after induction, the fish received a $4 \mathrm{~h} \mathrm{BrdU}$ pulse before kill. To accurately capture proliferative changes in the stem cell niche we quantified the number of BrdU+ cells in two domains of the cerebellum, the stem cell niche (domain 1) and the migratory zone where granule precursors are located (domain 2) (Fig. 7A). After a single heat induction, homozygous $h s p 70: d n$-fgfr 1 fish showed a significantly reduced number of proliferating cells in the stem cell niche $(n=4, p=0.0224)$ and proliferating granule precursors $(n=4, p=0.0464)$ compared with control fish (Fig. 7A). In addition, heterozygous $h s p 70: d n$ $f g f r 1$ fish showed a significantly reduced number of proliferating granule precursors $(n=4, p=0.0047)$ compared with control fish after one heat induction (supplemental Fig. S6, available at www.jneurosci.org as supplemental material).

We then studied the expression of Fgf receptors and downstream targets of the Fgf signaling pathway. Strong expression of $f g f r 2$ and moderate expression of $f g f r 3$ was found in cells that were interspersed in intermediate layer of the cerebellum (Fig. $7 C, D$ ). $f g f r 2$ was also expressed in the stem cell niche (Fig. $\left.7 C^{\prime}\right)$. No expression or very low expression of $f g f r l$ and $f g f r 4$ was detected in the adult cerebellum. Consistent with the $f g f r$ receptor expression, we detected tyrosine kinase receptor activity in glia in the 
intermediate layer with an antibody recognizing phosphorylated ERK (Fig. 7E; supplemental Fig. S6D, available at www. jneurosci.org as supplemental material). Despite high expression of $f g f r 2$ in the stem cell niche, we did not detect phosphorylated ERK in proliferating cells. Additionally, downstream targets of the Fgf signaling pathway were expressed in the adult cerebellum. spry2 was expressed in scattered cells in the intermediate layer whereas erm and spry 4 were detected in the granule cell layer (supplemental Fig. $\mathrm{S} 6 B, C$, available at www.jneurosci.org as supplemental material). Weak or no expression of sef, pea3, or dusp6 was detected in the adult cerebellum (data not shown). Together, these results indicate that blocking Fgf signaling significantly reduces cell proliferation in the cerebellum. Analysis of $f g f$ receptor expression, downstream targets of the Fgf signaling pathway, and tyrosine kinase receptor activity suggests that the Fgf signaling pathway activity is primarily in glia and granule cells.

\section{Discussion}

Here, we present the architecture and origin of a previously unknown neural stem cell niche. Our work provides a starting point for further studies on how adult neural stem cell niches arise during development and how they are maintained and regulated.

\section{Cerebellar stem cells in zebrafish retain neuroepithelial properties and ventricular contact}

The microenvironment is a major regulator of stem cells in vivo (Fuchs et al., 2004). In the adult mammalian telencephalon and during development, contact to the ventricle is a critical microenvironmental requirement to keep neural stem cells active (Bittman et al., 1997; Kosodo et al., 2004; Mirzadeh et al., 2008). In the zebrafish cerebellum, we find that that a portion of the anterior $\mathrm{RL}$, including its stem cells and microenvironment, persists into adulthood. The cerebellar stem cell niche is generated in two steps by morphogenetic movement and tissue growth. During embryonic and early juvenile stages, medially located RL progenitors and the IVth ventricle are shifted rostrally to form a small cerebellar dorsomedial recessus. During later juvenile stages, the RL progenitors and recessus are further separated from the IVth ventricle by growth of the granule cell layer. Importantly, molecular signals can reach the cerebellar stem cells through the CSF since the displaced ventricular space remains in contact with the IIIrd and IVth ventricle. Consistently, stem cell activity is inhibited and vanishes in the rodent cerebellar primordium once the neuroepithelium loses contact with the CSF and the IVth ventricle (Altman and Bayer, 1997). In contrast, the cerebellar stem cells in zebrafish maintain neuroepithelial properties, including Nestin expression, apical-basal polarization and contact to the IVth ventricle. Similarly, neural stem cells in the adult rodent telencephalic SVZ retain fundamental epithelial properties, such as apical-basal polarization and contact with the ventricular cavity (Mirzadeh et al., 2008). Together, this suggests that ventricular contact may be necessary for maintenance of neurogenic niches in vertebrates.
Fibroblast growth factor regulates stem cell activity in the adult cerebellum

Inhibition of Fgf signaling leads to a significant reduction of cell proliferation in the adult cerebellum. Fgf signaling is mediated through $f g f r 2$ and $f g f r 3$ in the cerebellum. Expression of downstream targets of the Fgf signaling pathway and tyrosine kinase receptor activity suggest that the most active Fgf signaling takes place in glia and granule cells. Although we found expression of $f g f r 2$ in the stem cell niche, we did not detect markers for high levels of Fgf signaling activity in the proliferating cells. This is in agreement with a recent study showing that Fgf activity is not associated with stem cell activity in the adult zebrafish brain (Topp et al., 2008). However, our results clearly show that stem cell activity is reduced when Fgf signaling is blocked, suggesting that Fgf signaling is important for stem cell regulation in the adult cerebellum. Interestingly, Fgfs ( $f g f 3, f g f 8 a$, and $f g f 8 b$ ) are expressed in the adult zebrafish cerebellum (Topp et al., 2008), although only in close proximity to the ventricle and not directly at the stem cell niche. It is therefore an attractive possibility that Fgfs might propagate through the ventricle in the cerebellum.

\section{Typical glia do not serve as stem cells in the adult}

\section{zebrafish cerebellum}

During development and in the adult CNS of mammals, cells with astroglial characteristics act as multipotent progenitors (Alvarez-Buylla et al., 2001). In contrast to mammals, radial glia persist in the adult CNS of nonmammalian vertebrates (GarcíaVerdugo et al., 2002; Kálmán, 2002; Zupanc and Clint, 2003). A prevailing view is the link between persisting radial glia and pronounced neural stem cell activity in nonmammalian vertebrates (Alvarez-Buylla et al., 2001; Götz et al., 2002). However, to our surprise, the proliferating progenitors in the cerebellum do not express canonical radial or astroglial markers, such as GFAP/ vimentin/3CB2/BLBP, but we did detect Nestin and other neural stem cell markers, indicating that they retain neuroepithelial rather than astroglial characteristics. We detected two populations of glia in the developing and adult zebrafish cerebellum. 

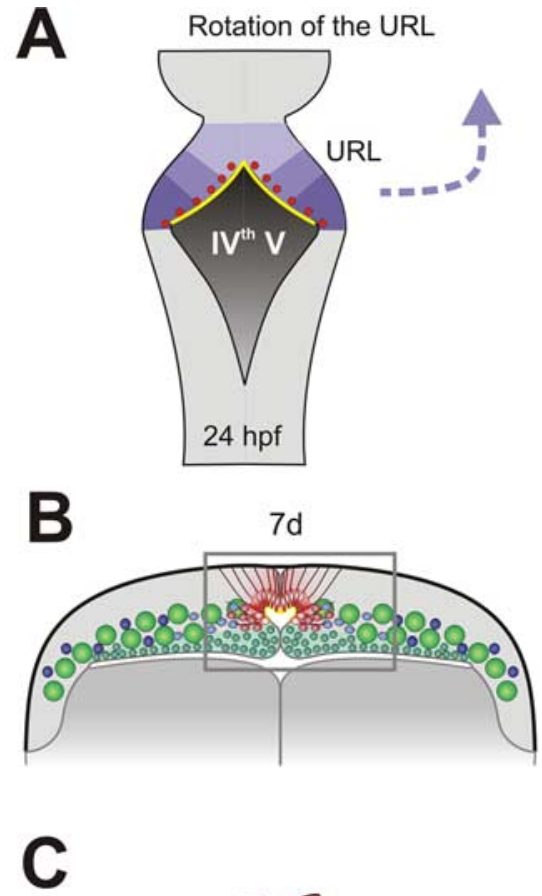

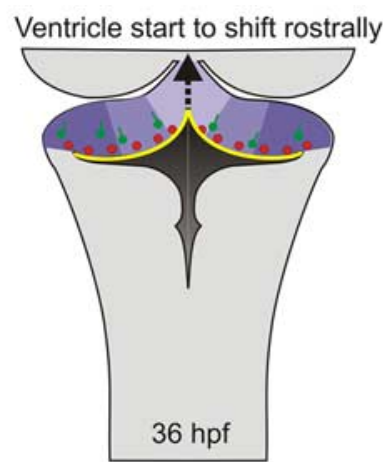

Growth of the GL

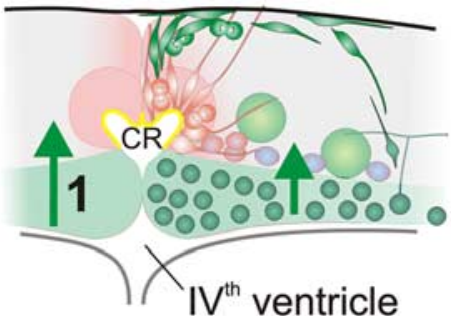

Remnant of ventricle remain at the midline

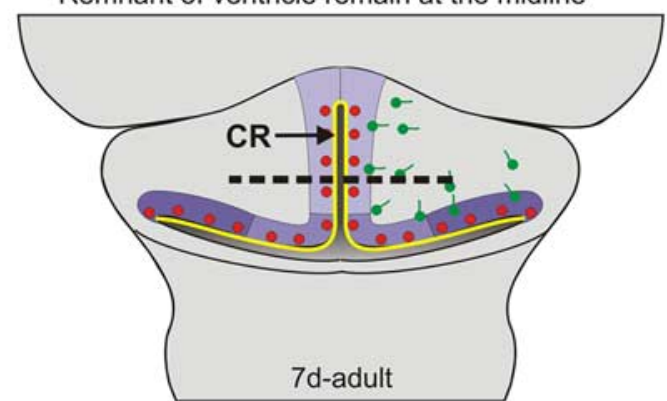

Growth of the ML
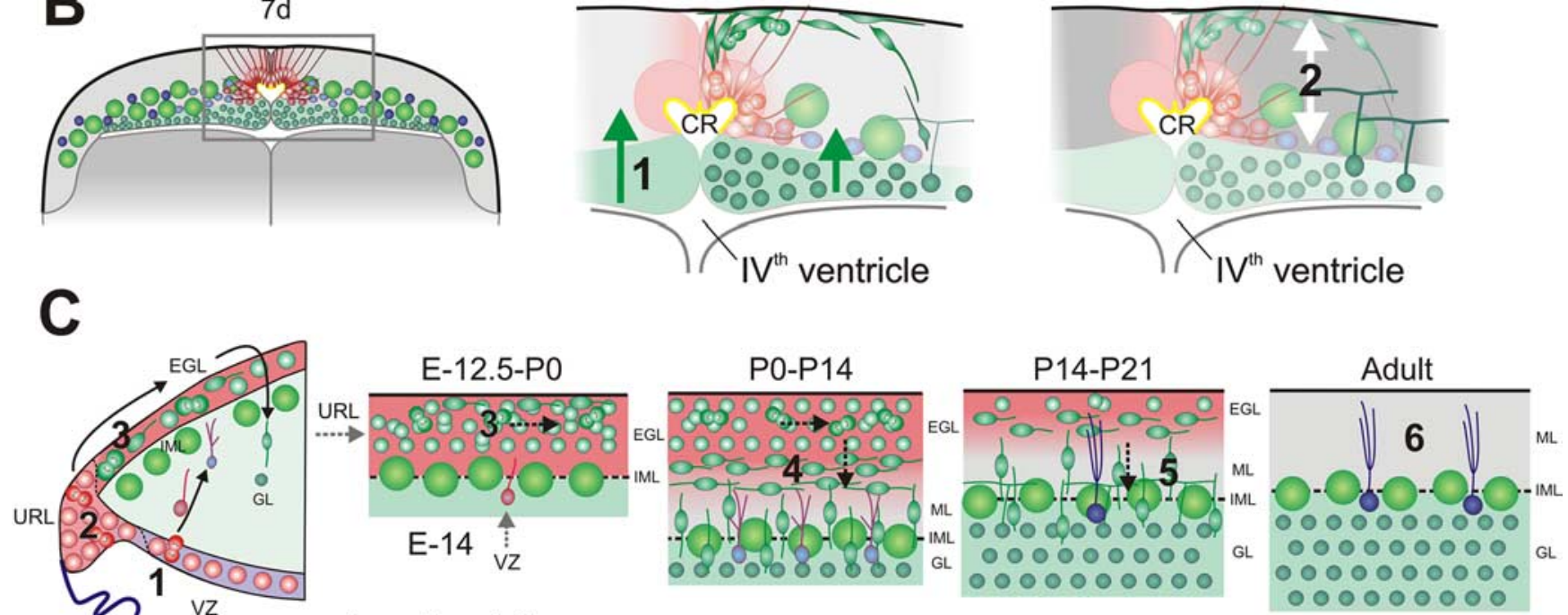

Juvenile-adult
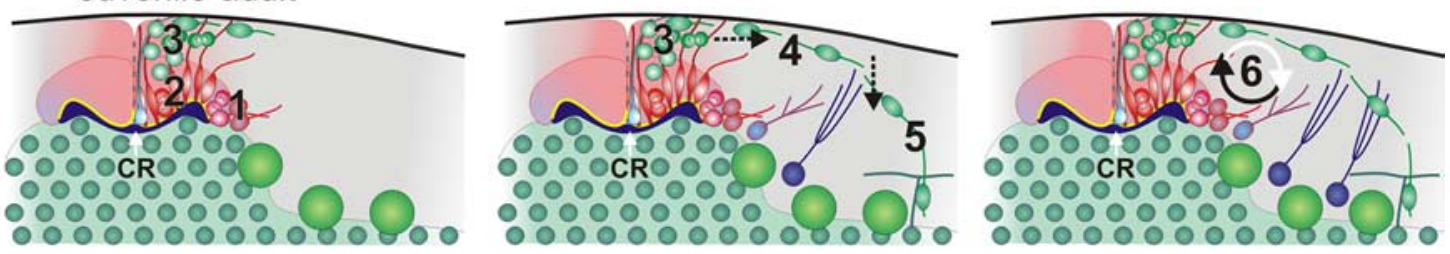

Figure 8. Schematic summary of cerebellar stem cell niche generation. $\boldsymbol{A}$, Morphogenetic rotation of rhombomere 1 and the cerebellar primordium (blue arrow). From $36 \mathrm{hpf}-2$ weeks, the dorsomedial part of the IVth ventricle is shifted anteriorly creating a dorsomedial extension of the IVth ventricle. Cerebellar progenitors (red cells) remain in contact with the extension of the IVth ventricle in the adult zebrafish. $\boldsymbol{B}$, Schematic summary of tissue growth and displacement of the stem cell niche and CR. Displacement of the stem cell niche through tissue growth begins $\sim 7 \mathrm{dpf}$. During juvenile stages there is vast generation of granule cells and massive expansion of the GL. The expanding GL separates the dorsomedial part of the IVth ventricle (yellow line) and the progenitors from the rest of the IVth ventricle (green arrows). The generated granule cells give rise to ascending axons, parallel fibers that course through the ML. The addition of axonal fiber mass to the ML further separates the progenitors from the roof plate/meninge (gray arrows). C, Comparison of the zebrafish adult stem cell niche and the cerebellar developmental program in mammals. 1, Ventricularly located progenitors generate glia precursors. 2, Progenitors in the URL feed the EGL with granule precursors. 3, Amplifying and tangentially migrating granule precursors in the EGL. 4-5, Granule precursors become postmitotic, differentiate and radially migrate into the GL. 6 , In the mammalian cerebellum, the URL and EGL are exhausted of their progenitors whereas in zebrafish glia and granule neurons are generated continuously. IVth V, IVth ventricle; CP, choroid plexus; CR, cerebellar recessus; EGL, external granule layer; GL, granule cell layer; IML, intermediate layer; ML, molecular layer; URL, upper rhombic lip.

Based on marker expression (S100 $\beta$, GFAP, vimentin) and morphology, one population of glia is likely to be equivalent to the Bergmann glia/Golgi epithelial cells of other vertebrates. Furthermore, we detected generation of $S 100 \beta$ glia in the juvenile and adult zebrafish cerebellum. Although it seems likely that these $S 100 \beta$ cells originated from the stem cell niche, we cannot unambiguously resolve this. The other glia type detected displays a distinct radial morphology and seems to serve as a scaffold during the initial migration of granule cells. Similarly, RC2/BLBP + radial glia provide a migratory pathway for the initial migration of cerebellar progenitors from the ventricular zone to the dorsal surface during early stages of mouse cerebellar development (Morales and Hatten, 2006).

\section{Zebrafish cerebellar stem cells display neural stem cell} markers and characteristics of upper rhombic lip progenitors Development of the zebrafish cerebellum follows a similar course to that observed in other vertebrates. Lineage tracing and fate map studies in zebrafish, chick and mouse have shown that extracerebellar and cerebellar cell types are produced in a strict temporal order with granule cells produced last (Wingate and Hatten, 1999; Köster and Fraser, 2001; Machold and Fishell, 2005; Wang et al., 2005). Cerebellar neurons and glia originate from two principal germinal zones, the upper rhombic lip (URL) and the VZ. Excitatory granule neurons and unipolar brush cells are generated by the RL whereas Purkinje cells and inhibitory neurons are generated from the VZ. 
Our results show that the cerebellar progenitors in the adult zebrafish originate from the URL. In vertebrates, the URL and its progenitors represent a dynamic structure located at the interface of the alar plate and roof plate (Wang and Zoghbi, 2001; Wingate, 2001). Induction of granule cell precursors depends on neuroepithelial cell interaction with the roof plate. Neuroepithelial precursors contacting the roof plate are transformed into tangentially migrating granule precursors. These undifferentiated URL precursors display a unipolar morphology and express Math1 and Nestin (Ben-Arie et al., 1997; Wingate and Hatten, 1999; Morales and Hatten, 2006). The nature of the progenitors of the URL, which continuously replenish the supply of migrating Math1 cells, is not understood (Wingate, 2005; Wilson and Wingate, 2006). In the adult zebrafish cerebellum, we find polarized progenitors displaying neural stem cell markers, such as Nestin, Sox2, Meis, and Musashi. These progenitors have a bipolar radial morphology and remain in contact with the roof plate and ventricle. Most of the cells generated from these progenitors turn into migrating granule precursors that initially display a unipolar morphology. We did not detect expression of atoh $1 a$ or atoh $1 b$ in the adult cerebellum. However, math 1 expression in mouse does not identify a spatially defined precursor pool as such, but rather temporal determination of these precursors (Wingate, 2005; Wilson and Wingate, 2006). Consistent with this, atoh1a or atoh1b expression in developing and juvenile zebrafish is detected transiently up to $7 \mathrm{dpf}$, after which it is gradually lost (data not shown).

\section{Continuous generation of granule neurons and conserved migratory patterns in the adult zebrafish cerebellum}

In mammals and birds, the granule precursors migrate from the URL and pile up over the cerebellar surface to form a highly proliferative second germinal zone, the external granule layer (EGL) (Fig. 8C). In zebrafish, the granule cells leave the germinal zone in the upper rhombic lip and migrate and differentiate $\sim 48$ hpf (Köster and Fraser, 2001; Volkmann et al., 2008). A prominent EGL does not form during cerebellar development in zebrafish. EGL granule precursors in rodents and chick express the transcription factors math1, Zic1, Zic3, and Pax6 (Aruga et al., 1994; Lin and Cepko, 1998; Engelkamp et al., 1999). After a second wave of proliferation, the EGL precursors generate granule cells that migrate radially inwards to form the internal granule cell layer. Postmitotic granule precursors in the inner EGL express the neuronal differentiation bHLH protein Neurod (Miyata et al., 1999). Likewise, Zic1, Zic3, Pax6, and Neurod are expressed by migrating granule precursors in the adult zebrafish cerebellum. Neurod is detected in migrating nonproliferating cells in the adult zebrafish cerebellum. In addition, the migratory behavior of granule precursors in the adult zebrafish is very similar to that reported in the EGL of mammals and birds (Wang and Zoghbi, 2001; Sotelo, 2004). The subsequent tangential ventrolateral migration in zebrafish resembles the migratory behavior of GCPs in the EGL of rodents. In the EGL of rodents, GCPs first migrate tangentially in a medial to lateral direction before turning into the deep layers of the EGL where they migrate radially along Bergmann glia inwards to the IGL (Altman and Bayer, 1997). However, in zebrafish we do not detect GCP migration along radial glia in the IGL. Thus, our results show that the cerebellar stem cells give rise to precursors that express transcription factors and markers typical for granule precursors. Furthermore, our results suggest that migratory patterns are also conserved in the zebrafish cerebellum and that the scarce EGL in zebrafish is a consequence of the relative emphasis of secondary amplification.

\section{Conclusions}

In contrast to the predominant view, adult neural stem cells in the zebrafish show more neuroepithelial characteristics than glial. Nevertheless, retained epithelial properties and ventricular contact still seem to be critical determinants for maintaining neural stem cell activity in vertebrates. The adult zebrafish cerebellar stem cell niche recapitulates many of the strictly sequential events seen during granule cell development in mammals (Fig. 8C). However, in zebrafish the generation of granule cells is a dynamic life-long process. Understanding the cellular and molecular events in how stem cell niches have evolved or have been lost in different lineages of vertebrates will give valuable insight into how stem cells are maintained and regulated in the CNS.

\section{References}

Adolf B, Chapouton P, Lam CS, Topp S, Tannhäuser B, Strähle U, Götz M, Bally-Cuif L (2006) Conserved and acquired features of adult neurogenesis in the zebrafish telencephalon. Dev Biol 295:278-293.

Altman J, Bayer SA (1997) Development of the cerebellar system: in relation to its evolution, structure, and functions. Boca Raton, FL: CRC.

Alvarez-Buylla A, Lim DA (2004) For the long run: maintaining germinal niches in the adult brain. Neuron 41:683-686.

Alvarez-Buylla A, García-Verdugo JM, Tramontin AD (2001) A unified hypothesis on the lineage of neural stem cells. Nat Rev Neurosci 2:287-293.

Aruga J, Yokota N, Hashimoto M, Furuichi T, Fukuda M, Mikoshiba K (1994) A novel zinc finger protein, zic, is involved in neurogenesis, especially in the cell lineage of cerebellar granule cells. J Neurochem 63:1880-1890.

Ben-Arie N, Bellen HJ, Armstrong DL, McCall AE, Gordadze PR, Guo Q, Matzuk MM, Zoghbi HY (1997) Math1 is essential for genesis of cerebellar granule neurons. Nature 390:169-172.

Bernardos RL, Raymond PA (2006) GFAP transgenic zebrafish. Gene Expr Patterns 6:1007-1013.

Bittman K, Owens DF, Kriegstein AR, LoTurco JJ (1997) Cell coupling and uncoupling in the ventricular zone of developing neocortex. J Neurosci 17:7037-7044.

Console-Bram LM, Fitzpatrick-McElligott SG, McElligott JG (1996) Distribution of GAP-43 mRNA in the immature and adult cerebellum: a role for GAP-43 in cerebellar development and neuroplasticity. Brain Res Dev Brain Res 95:97-106.

Costagli A, Kapsimali M, Wilson SW, Mione M (2002) Conserved and divergent patterns of Reelin expression in the zebrafish central nervous system. J Comp Neurol 450:73-93.

Decotto E, Spradling AC (2005) The Drosophila ovarian and testis stem cell niches: similar somatic stem cells and signals. Dev Cell 9:501-510.

Doetsch F, Scharff C (2001) Challenges for brain repair: insights from adult neurogenesis in birds and mammals. Brain Behav Evol 58:306-322.

Engelkamp D, Rashbass P, Seawright A, van Heyningen V (1999) Role of Pax6 in development of the cerebellar system. Development 126:3585-3596.

Fuchs E, Tumbar T, Guasch G (2004) Socializing with the neighbors: stem cells and their niche. Cell 116:769-778.

García-Verdugo JM, Ferrón S, Flames N, Collado L, Desfilis E, Font E (2002) The proliferative ventricular zone in adult vertebrates: a comparative study using reptiles, birds, and mammals. Brain Res Bull 57:765-775.

Götz M, Huttner WB (2005) The cell biology of neurogenesis. Nat Rev Mol Cell Biol 6:777-788.

Götz M, Hartfuss E, Malatesta P (2002) Radial glial cells as neuronal precursors: a new perspective on the correlation of morphology and lineage restriction in the developing cerebral cortex of mice. Brain Res Bull 57:777-788.

Graham V, Khudyakov J, Ellis P, Pevny L (2003) SOX2 functions to maintain neural progenitor identity. Neuron 39:749-765.

Grandel H, Kaslin J, Ganz J, Wenzel I, Brand M (2006) Neural stem cells and neurogenesis in the adult zebrafish brain: origin, proliferation dynamics, migration and cell fate. Dev Biol 295:263-277.

Hans S, Kaslin J, Freudenreich D, Brand M (2009) Temporally-controlled site-specific recombination in zebrafish. PLoS ONE 4:e4640.

Hoshino M, Nakamura S, Mori K, Kawauchi T, Terao M, Nishimura YV, Fukuda A, Fuse T, Matsuo N, Sone M, Watanabe M, Bito H, Terashima T, 
Wright CV, Kawaguchi Y, Nakao K, Nabeshima Y (2005) Ptfla, a bHLH transcriptional gene, defines GABAergic neuronal fates in cerebellum. Neuron 47:201-213.

Johanson CE, Duncan JA 3rd, Klinge PM, Brinker T, Stopa EG, Silverberg GD (2008) Multiplicity of cerebrospinal fluid functions: New challenges in health and disease. Cerebrospinal Fluid Res 5:10.

Kálmán M (2002) GFAP expression withdraws-a trend of glial evolution? Brain Res Bull 57:509-511.

Kaneko Y, Sakakibara S, Imai T, Suzuki A, Nakamura Y, Sawamoto K, Ogawa Y, Toyama Y, Miyata T, Okano H (2000) Musashil: an evolutionally conserved marker for CNS progenitor cells including neural stem cells. Dev Neurosci 22:139-153.

Kaslin J, Nystedt JM, Ostergård M, Peitsaro N, Panula P (2004) The orexin/ hypocretin system in zebrafish is connected to the aminergic and cholinergic systems. J Neurosci 24:2678-2689.

Kaslin J, Ganz J, Brand M (2008) Proliferation, neurogenesis and regeneration in the non-mammalian vertebrate brain. Philos Trans R Soc Lond B Biol Sci 363:101-122.

Kosodo Y, Röper K, Haubensak W, Marzesco AM, Corbeil D, Huttner WB (2004) Asymmetric distribution of the apical plasma membrane during neurogenic divisions of mammalian neuroepithelial cells. EMBO J 23:2314-2324.

Köster RW, Fraser SE (2001) Direct imaging of in vivo neuronal migration in the developing cerebellum. Curr Biol 11:1858-1863.

Lee Y, Grill S, Sanchez A, Murphy-Ryan M, Poss KD (2005) Fgf signaling instructs position-dependent growth rate during zebrafish fin regeneration. Development 132:5173-5183.

Lendahl U, Zimmerman LB, McKay RD (1990) CNS stem cells express a new class of intermediate filament protein. Cell 60:585-595.

Lin JC, Cepko CL (1998) Granule cell raphes and parasagittal domains of Purkinje cells: complementary patterns in the developing chick cerebellum. J Neurosci 18:9342-9353.

Machold R, Fishell G (2005) Math1 is expressed in temporally discrete pools of cerebellar rhombic-lip neural progenitors. Neuron 48:17-24.

Mahler J, Driever W (2007) Expression of the zebrafish intermediate neurofilament Nestin in the developing nervous system and in neural proliferation zones at postembryonic stages. BMC Dev Biol 7:89.

Maricich SM, Herrup K (1999) Pax-2 expression defines a subset of GABAergic interneurons and their precursors in the developing murine cerebellum. J Neurobiol 41:281-294.

McElligott JG, Beeton P, Polk J (1998) Effect of cerebellar inactivation by lidocaine microdialysis on the vestibuloocular reflex in goldfish. J Neurophysiol 79:1286-1294.

Mirzadeh Z, Merkle FT, Soriano-Navarro M, Garcia-Verdugo JM, AlvarezBuylla A (2008) Neural stem cells confer unique pinwheel architecture to the ventricular surface in neurogenic regions of the adult brain. Cell Stem Cell 3:265-278.

Miyata T, Maeda T, Lee JE (1999) NeuroD is required for differentiation of the granule cells in the cerebellum and hippocampus. Genes Dev 13:1647-1652.
Morales D, Hatten ME (2006) Molecular markers of neuronal progenitors in the embryonic cerebellar anlage. J Neurosci 26:12226-12236.

Mueller T, Wullimann MF (2002) Expression domains of neuroD (nrd) in the early postembryonic zebrafish brain. Brain Res Bull 57:377-379.

Nagai T, Aruga J, Takada S, Günther T, Spörle R, Schughart K, Mikoshiba K (1997) The expression of the mouse Zic1, Zic2, and Zic3 gene suggests an essential role for Zic genes in body pattern formation. Dev Biol 182:299-313.

Partanen J (2007) FGF signalling pathways in development of the midbrain and anterior hindbrain. J Neurochem 101:1185-1193.

Pesold C, Impagnatiello F, Pisu MG, Uzunov DP, Costa E, Guidotti A, Caruncho HJ (1998) Reelin is preferentially expressed in neurons synthesizing gamma-aminobutyric acid in cortex and hippocampus of adult rats. Proc Natl Acad Sci U S A 95:3221-3226.

Rhinn M, Picker A, Brand M (2006) Global and local mechanisms of forebrain and midbrain patterning. Curr Opin Neurobiol 16:5-12.

Sgaier SK, Millet S, Villanueva MP, Berenshteyn F, Song C, Joyner AL (2005) Morphogenetic and cellular movements that shape the mouse cerebellum; insights from genetic fate mapping. Neuron 45:27-40.

Sotelo C (2004) Cellular and genetic regulation of the development of the cerebellar system. Prog Neurobiol 72:295-339.

Topp S, Stigloher C, Komisarczuk AZ, Adolf B, Becker TS, Bally-Cuif L (2008) Fgf signaling in the zebrafish adult brain: association of Fgf activity with ventricular zones but not cell proliferation. J Comp Neurol 510:422-439.

Volkmann K, Rieger S, Babaryka A, Köster RW (2008) The zebrafish cerebellar rhombic lip is spatially patterned in producing granule cell populations of different functional compartments. Dev Biol 313:167-180.

Wang VY, Zoghbi HY (2001) Genetic regulation of cerebellar development. Nat Rev Neurosci 2:484-491.

Wang VY, Rose MF, Zoghbi HY (2005) Math1 expression redefines the rhombic lip derivatives and reveals novel lineages within the brainstem and cerebellum. Neuron 48:31-43.

Westerfield M (2000) The zebrafish book. A guide for the laboratory use of zebrafish Danio (Brachydanio) rerio, Ed 4. Eugene, OR: ZFIN.

Wilson LJ, Wingate RJ (2006) Temporal identity transition in the avian cerebellar rhombic lip. Dev Biol 297:508-521.

Wingate R (2005) Math-Map(ic)s. Neuron 48:1-4.

Wingate RJ (2001) The rhombic lip and early cerebellar development. Curr Opin Neurobiol 11:82-88.

Wingate RJ, Hatten ME (1999) The role of the rhombic lip in avian cerebellum development. Development 126:4395-4404.

Zhang Y, Buchholz F, Muyrers JP, Stewart AF (1998) A new logic for DNA engineering using recombination in Escherichia coli. Nat Genet 20:123-128.

Zupanc GK, Clint SC (2003) Potential role of radial glia in adult neurogenesis of teleost fish. Glia 43:77-86.

Zupanc GK, Hinsch K, Gage FH (2005) Proliferation, migration, neuronal differentiation, and long-term survival of new cells in the adult zebrafish brain. J Comp Neurol 488:290-319. 